\title{
An Inherited Bleeding Disorder Linked to a Defective Interaction between ADP and Its Receptor on Platelets \\ Its Influence on Glycoprotein IIb-IIla Complex Function
}

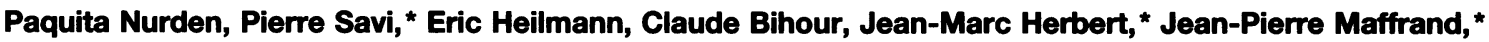 \\ and Alan Nurden \\ Unité de Recherche Associée 1464 Centre National de la Recherche Scientifique, Hôpital Cardiologique, 33604 Pessac and \\ * Sanofi Research, 31036 Toulouse, France
}

\begin{abstract}
Much discussion has concerned the central role of ADP in platelet aggregation. We now describe a patient (M. L.) with an inherited bleeding disorder whose specific feature is that ADP induces a limited and rapidly reversible platelet aggregation even at high doses. Platelet shape change and other hemostatic parameters were unmodified. A receptor defect was indicated, for, while epinephrine normally lowered

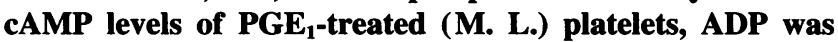
without effect. The binding of $\left[{ }^{3} \mathrm{H}\right] 2$-methylthio-ADP decreased from $836 \pm 126$ molecules/platelet for normals to $30 \pm 17$ molecules/platelet for the patient. Flow cytometry confirmed that ADP induced a much lower fibrinogen binding to (M. L.) platelets. Nonetheless, the binding in whole blood of activation-dependent monoclonal antibodies showed that some activation of GP IIb-IIIa complexes by ADP was occurring. Platelets of a patient with type I Glanzmann's thrombasthenia bound $\left[{ }^{3} \mathrm{H}\right] 2$-methylthio-ADP and responded normally to $A D P$ in the presence of $P_{1} E_{1}$. Electron microscopy showed that ADP-induced aggregates of (M. L.) platelets were composed of loosely bound shapechanged platelets with few contact points. Thus this receptor defect has a direct influence on the capacity of platelets to bind to each other in response to ADP. (J. Clin. Invest. 1995. 95:1612-1622.) Key words: platelet aggregation - ADP receptor $\bullet$ inherited disorder $\cdot$ platelet activation $\cdot$ flow cytometry
\end{abstract}

\section{Introduction}

Blood platelets fulfill an essential role in primary hemostasis by their capacity $(a)$ to adhere to exposed subendothelium, $(b)$ to aggregate and effect thrombus formation, and $(c)$ to generate

Part of this work was presented at the XIVth Congress of the International Society on Thrombosis and Haemostasis in New York, July 49, 1993, and has been published in abstract form (1993. Thromb. Haemostasis. 69:1189a).

Address correspondence to Alan T. Nurden, Director, Unité de Recherche Associée 1464 Central National de la Recherche Scientifique, Hôpital Cardiologique, 33604 Pessac, France. Phone: 33-56-55-68-08; FAX: 33-56-55-65-31.

Received for publication 22 July 1994 and in revised form 9 November 1994.

J. Clin. Invest.

(C) The American Society for Clinical Investigation, Inc.

0021-9738/95/04/1612/11 \$2.00

Volume 95, March 1995, 1612-1622 procoagulant activity. It is now known that aggregation is mediated by a common mechanism that involves the binding of fibrinogen, or other adhesive proteins, to GP IIb-IIIa complexes of platelets $(1,2)$. A variety of soluble agonists stimulate platelet aggregation by reacting with distinct populations of primary receptors in the platelet membrane. Among these is ADP, long considered to be a key stimulus for platelets in vivo (see reference 3). ADP has at least two effects on human platelets (data reviewed in references 4 and 5). Firstly, it induces shape change and exposure of fibrinogen-binding determinants on GP IIbIIIa complexes leading to aggregation. Secondly, it inhibits platelet adenylate cyclase and prevents the accumulation of cAMP. Controversy exists as to the nature of the ADP-binding site(s) on platelets and, indeed, some evidence points to the above effects being mediated by distinct receptors for ADP in the platelet membrane. Perhaps not surprisingly, data pertaining to the physiologic role of ADP in thrombus formation in vivo has been difficult to obtain and, as a result, the evidence for the importance of ADP is mostly circumstantial in nature.

Studies on inherited platelet disorders have been instrumental in establishing the role of membrane glycoproteins in platelet adhesion and aggregation mechanisms, while the bleeding syndromes which accompany the congenital deficiencies of adhesive proteins such as fibrinogen and $\mathrm{vWf}$ also corroborate the role of these proteins in hemostasis (see reference 6). Defects in the storage of adenine nucleotides in dense granules of platelets in storage pool disease give rise to a defective aggregation response to collagen and other stimuli through the absence of the potentiating effect of ADP released during secretion $(6,7)$. Studies on Glanzmann's thrombasthenia, where patients possess platelets with qualitative and/or quantitative defects of GP IIIbIIIa complexes, have yielded much information on the fine details of the platelet aggregation mechanism $(6,8)$. However, despite this progress, relatively little is known about the pathology of primary receptors on platelets or of the activation mechanisms that lead to the expression of adhesive protein binding determinants on GP IIb-IIIa complexes. Recently, Cattaneo et al. (9) reported a congenital defect of platelet function characterized by a severe impairment of platelet responses to ADP. We now report our studies on a family with what may be a similar abnormality in that ADP induces a small and rapidly reversible platelet aggregation even at high doses. This was associated with a markedly reduced binding of $\left[{ }^{3} \mathrm{H}\right] 2$-methylthio-ADP $\left(\left[{ }^{3} \mathrm{H}\right] 2-\mathrm{MeS}-\mathrm{ADP}\right)^{1}$ to platelets and a failure of

1. Abbreviations used in this paper: $\mathrm{CP} / \mathrm{CPK}$, creatine phosphate/creatine phosphokinase; $\left[{ }^{3} \mathrm{H}\right] 2-\mathrm{MeS}-\mathrm{ADP},\left[{ }^{3} \mathrm{H}\right]$ 2-methylthio-ADP; PFA, paraformaldehyde; PRP, platelet-rich plasma; RIBS, receptor-induced binding site; TRAP-14-mer, thrombin receptor-activating peptide. 
ADP to lower the content of cyclic AMP of platelets preincubated with $\mathrm{PGE}_{1}$. Specifically, we have used flow cytometry to examine the ability of ADP to induce fibrinogen binding to the patient's platelets by using a range of mAbs to study the expression of activation-dependent epitopes on GP IIb-IIIa. Our results suggest that this particular receptor defect interferes directly with the ability of ADP to modulate GP IIb-IIIa function.

\section{Methods}

\section{Case histories}

The patient (M. L.) is a 61-yr-old Caucasian man with a spasmodic history of brief episodes of excessive bleeding. The first severe episode occurred at the age of 17 when, after a minor accident, he developed a subretinal hemorrhage which led to the loss of an eye. A second major episode occurred during surgery performed when he was 28-yr-old. A third episode occurred during middle age when pulmonary bleeding led to the development of hemoptysis. Several other members of his family have reported excessive bleeding. Especially affected was his sister (Ma. L.), who died from an unrelated illness in 1989. An uncle reportedly deceased many years ago as a result of a severe epistaxis. His father died from bleeding after a motor accident; we have no information on his mother, who died during his early childhood. Consanguinity exists in the family, for his parents were cousins. His only child, a daughter (C. L.), was also studied by us. She has not experienced unusual bleeding. The patient (M. L.) has been followed since 1975 . His platelet count $(180,000-250,000 / \mu 1)$ and the number of red and white cells have always been normal. His Ivy bleeding time is consistently $>20 \mathrm{~min}$ (normal values $<10 \mathrm{~min}$ ). Other hemostatic parameters, including coagulation and fibrinolytic pathways, are consistently normal. Thrombin-induced clot retraction is normal. Tests for antiplatelet antibodies have been performed on several occasions and were negative. On one occasion, platelets from a Glanzmann's thrombasthenia patient (F. La.) were studied in parallel. This patient belongs to the type I category, with $<5 \%$ of normal platelet levels of GP IIb-IIIa complexes and an absence of clot retraction. Patient (F. La.), unrelated to (M. L.) and his family, is No. 9 in the report of 64 cases by George et al. (8). Hospital staff served as normal controls. Informed consent was obtained from the patients and the study performed in accordance with the declaration of Helsinki.

\section{Platelet aggregation.}

For studies on platelet-rich plasma (PRP), venous blood was anticoagulated with sodium citrate $(0.38 \% \mathrm{wt} / \mathrm{vol})$ and PRP obtained by centrifugation at $120 \mathrm{~g}$ for $10 \mathrm{~min}$. Aggregation was performed in a PAP-4 aggregometer (Bio/Data Corp., Wellcome Laboratories, Paris, France). Counts ranged between 200 and $300 \times 10^{3}$ platelets/ $\mu l$ and were adjusted by diluting with platelet-poor plasma prepared by centrifuging the remaining red cells and buffy coat at $12,000 \mathrm{~g}$. Stimuli used included 2-50 $\mu$ M ADP (Sigma Chemical Co., St Louis, MO), $500 \mu \mathrm{g} / \mathrm{ml}$ arachidonic acid (Nu Chek Prep, Elysian, MN), 25 and $50 \mu \mathrm{g} / \mathrm{ml}$ collagen (Laboratoire Stago, Paris, France), and $1.5 \mathrm{mg} / \mathrm{ml}$ ristocetin $(\mathrm{H}$. Lundbeck \& Co., Copenhagen, Denmark). Activation via the thrombin receptor was studied using commercially synthesized thrombin-receptor-activating peptide (TRAP-14-mer; Neosystem SA, Strasbourg, France). This peptide corresponds to the first 14 amino acids of the tethered $\mathrm{NH}_{2}$-terminal sequence exposed after cleavage of the receptor by thrombin (10). TRAP-14-mer was used within a 6-50 $\mu \mathrm{M}$ concentration range in PRP. The aggregation of washed platelets by $\alpha$-thrombin (Fibrindex; Ortho Diagnostic Systems Inc., Raritan, NJ) was studied according to the procedures published by Hourdillé et al. (11).

\section{Binding of $\left[{ }^{3} \mathrm{H}\right]-2-\mathrm{MeS}-\mathrm{ADP}$ to platelets}

[ $\left.{ }^{3} \mathrm{H}\right]-2-M e S-A D P(6 \mathrm{Ci} / \mathrm{mmol}$ ) was purchased from Dositek (Orsay, France). Analysis of the recrystallized product by high pressure liquid chromatography revealed that it was $>95 \%$ pure. Binding studies were performed using washed platelets prepared as described by Hourdillé et al. (11) and resuspended at $1.25 \times 10^{9} / \mathrm{ml}$ in $145 \mathrm{mM} \mathrm{NaCl}, 5 \mathrm{mM}$ $\mathrm{KCl}, 0.1 \mathrm{mM} \mathrm{MgCl}_{2}, 5.5 \mathrm{mM}$ glucose, $15 \mathrm{mM}$ Hepes, and $5 \mathrm{mM}$ EDTA, pH 7.4 (Tyrode's-EDTA). Triplicate samples $(0.2 \mathrm{ml})$ were mixed with 0-20 nM [ $\left.{ }^{3} \mathrm{H}\right]-2-\mathrm{MeS}-\mathrm{ADP}$. Incubations were continued without agitation for $15 \mathrm{~min}$ at $37^{\circ} \mathrm{C}$. They were terminated by the addition of $3 \mathrm{ml}$ ice-cold Tyrode's-EDTA followed by rapid vacuum filtration over glass fiber filters (Filtermats 11734; Skatron Inc., Sterling, VA). Filters were then washed twice with $5 \mathrm{ml}$ ice-cold Tyrode's-EDTA, dried, and the radioactivity measured in a scintillation counter (Rackbeta model 1215; Pharmacia LKB Biotechnology Inc., Uppsala, Sweden ). Nonspecific binding was assessed by performing parallel incubations in the presence of excess unlabeled ADP ( $1 \mathrm{mM})$. Specific binding was defined as the difference between total binding and nonspecific binding. Data were analyzed using a nonlinear regression program (12) and Scatchard analysis was performed.

\section{Measurement of platelet adenylate cyclase activity}

Measurements of cAMP were performed by radioimmunoassay, using kits supplied by Amersham International (Little Chalfont, United Kingdom). The procedure has been previously detailed by us (13). In brief, $2 \mathrm{ml}$ citrated PRP $\left(4 \times 10^{8}\right.$ platelets $\left./ \mathrm{ml}\right)$ were mixed with an equal volume of buffer containing $15 \mathrm{mM}$ Tris, $120 \mathrm{mM} \mathrm{NaCl}, 4 \mathrm{mM} \mathrm{KCl}$, $1.6 \mathrm{mM} \mathrm{MgSO}_{4}, 2 \mathrm{mM} \mathrm{NaH}_{2} \mathrm{PO}_{4}, 10 \mathrm{mM}$ glucose, and $1.5 \mathrm{mM}$ isobutylmethylxanthine, pH 7.4 (Sigma Chemical Co.). After incubation at $37^{\circ} \mathrm{C}$ for $1 \mathrm{~min}$, samples $(500 \mu \mathrm{l})$ were withdrawn to permit the determination of the basal level of cAMP in the platelets. Platelets in the remaining suspensions were then challenged with $10 \mu \mathrm{M} \mathrm{PGE}_{1}$ (Sigma Chemical Co.) and $500 \mu \mathrm{l}$ samples withdrawn $3 \mathrm{~min}$ later for cAMP determination. Equivalent suspensions of $\mathrm{PGE}_{1}$-treated platelets were incubated with $10 \mu \mathrm{M}$ ADP, $10 \mu \mathrm{M}$ epinephrine (Laboratoire Stago), or buffer and incubation continued for $3 \mathrm{~min}$. Again, $0.5-\mathrm{ml}$ samples were taken for the analysis of cAMP levels. In all samples, incubation was stopped by the addition of $50 \mu \mathrm{l} 6 \mathrm{~N} \mathrm{HCl}$ and $50 \mu \mathrm{l} 0.2 \mathrm{M}$ EDTA. Cyclic AMP was extracted using an adaptation of the procedure described by Meurs et al. (14). In brief, samples were boiled for $5 \mathrm{~min}$ in a waterbath and, after rapid cooling on ice, they were centrifuged at $10,000 \mathrm{~g}$ for $5 \mathrm{~min}$. Volumes $(200 \mu \mathrm{l})$ of the clarified supernatants were shaken with $60 \mathrm{mg} \mathrm{CaCO}$. After $15 \mathrm{~min}$ at room temperature, the samples were centrifuged once more at $10,000 \mathrm{~g}$ for $5 \mathrm{~min}$. Aliquots $(100 \mu 1)$ of the final supernatant were used for cAMP determination.

\section{Flow cytometry studies}

A number of different procedures were used to assess the glycoprotein content of (M. L.) platelets and the activation state of GP IIb-IIIa complexes in response to ADP and other agonists.

Studies on paraformaldehyde (PFA)-fixed platelets. Venous blood (6 vol) was anticoagulated with acid-citrate-dextrose NIH formula A ( $38 \mathrm{mM}$ citric acid, $61 \mathrm{mM}$ trisodium citrate, $136 \mathrm{mM}$ glucose, $\mathrm{pH} 6.5$ ) ( $1 \mathrm{vol}$ ). PRP was obtained by centrifugation at $120 \mathrm{~g}$ for $15 \mathrm{~min}$ at room temperature. In brief, platelets were washed three times in 102 $\mathrm{mM} \mathrm{NaCl}, 5 \mathrm{mM} \mathrm{KCl}, 2 \mathrm{mM} \mathrm{CaCl}{ }_{2}, 1 \mathrm{mM} \mathrm{MgCl}_{2}, 0.35 \%$ (wt/vol) BSA, $5 \mathrm{mM}$ glucose, $36 \mathrm{mM}$ citric acid, $0.1 \mu \mathrm{M} \mathrm{PGE}_{1}$, and $25 \mu \mathrm{g} / \mathrm{ml}$ apyrase (Sigma Chemical Co.), pH 6.5, and resuspended at $10^{8}$ platelets/ml in Tyrode's buffer, $\mathrm{pH} 7.4$, containing $2 \mathrm{mM} \mathrm{CaCl}$. Some samples were incubated without stirring at $37^{\circ} \mathrm{C}$ with $0.5 \mathrm{U} / \mathrm{ml}$ thrombin for $10 \mathrm{~min}$ as described by Hourdillé et al. (11). Unstimulated and thrombin-treated platelets were fixed with an equal volume of $2 \%$ (wt/ vol) PFA for $30 \mathrm{~min}$ at room temperature. After further washing, the platelets $\left(10^{8} / \mathrm{ml}\right)$ were incubated with one of the following murine mAbs: AP-2 ( $10 \mu \mathrm{g} / \mathrm{ml})$ directed against the GP IIb-IIIa complex (15); Bx-1 (23 $\mu \mathrm{g} / \mathrm{ml})$ directed against the $\alpha$-chain of GP Ib (11); or VH10 ( $5 \mu \mathrm{g} / \mathrm{ml}$ ) directed against GMP-140 (11).

Fibrinogen binding to platelets stimulated with ADP. This was first evaluated in citrated PRP under conditions close to those used to test platelet aggregation. In particular, these experiments were designed to evaluate whether GP IIb-IIIa complexes in the platelets of the patient (M. L.) were able to bind fibrinogen in the period immediately after the addition of ADP. Aliquots ( $100 \mu \mathrm{l})$ of PRP were incubated with 10 
$\mu \mathrm{M}$ ADP at $37^{\circ} \mathrm{C}$ without stirring. A 1:50 dilution of rabbit antifibrinogen IgG (Dako SA, Glostrup, Denmark) was added to the suspension at different times ( $10 \mathrm{~s}$ to $1 \mathrm{~min}$ ) after the addition of the ADP. 2 min later, this was followed by the addition of FITC-conjugated affinity purified $\mathrm{F}\left(\mathrm{ab}^{\prime}\right)_{2}$ fragments of a sheep anti-rabbit IgG (Silenus Laboratories Pty, Ltd., Hawthorn, Australia ). After a further $8 \mathrm{~min}$, the suspension was diluted to $1 \mathrm{ml}$ in PBS buffer and directly analyzed in the flow cytometer (see below). In a second approach, fibrinogen (Kabi, AB Stockholm, Sweden) was conjugated with FITC (Aldrich Chemical Co., Strasbourg, France) at $\mathrm{pH} 9$ according to standard procedures, and separated from unbound FITC by passage across a PD-10 column (Pharmacia LKB Biotechnology Inc.). The FITC/fibrinogen molar ratio was 3.2 and the labeled fibrinogen $90 \%$ clottable with thrombin. For these experiments, washed platelets were prepared as described above and incubated $\left(10^{8} / \mathrm{ml}\right)$ with $400 \mu \mathrm{g} / \mathrm{ml}$ FITC-fibrinogen and $10 \mu \mathrm{M}$ ADP at $37^{\circ} \mathrm{C}$ without stirring for periods of up to $15 \mathrm{~min}$. The incubation was stopped at different times by diluting with PBS, $\mathrm{pH} 7.4$, and rapid fixation with $1 \%$ (wt/vol) PFA. Control incubations were performed in the absence of ADP.

Binding of antibodies recognizing activation-dependent epitopes on platelets. A panel of murine mAbs was used. PAC-1 (an IgM) a gift from Dr. S. Shattil (Philadelphia, PA) recognizes an activation-dependent epitope on GP IIb-IIIa $(16,17)$. It was used at a final concentration of $6.25 \mu \mathrm{g} / \mathrm{ml}$ purified IgM. AP-6 (an IgM) donated by Dr. T. J. Kunicki (Scripps Research Institute, La Jolla, CA) was generated by immunizing a mouse with the $\beta_{3(211-221)}$ peptide, it also exhibits activation-dependent binding to GP IIb-IIIa on intact platelets (18). It was used as ascites fluid (dilution 1/1,000). D33C was provided by Dr. G. Marguerie (C.E.A., Grenoble, France). D33C has the unusual property of itself promoting the activation of GP IIb-IIIa while binding with a higher affinity to the activated complex (19). It was used as purified IgG at $10 \mu \mathrm{g} / \mathrm{ml}$. F26 was provided by Dr. H. Gralnick (National Institutes of Health, Bethesda, MD) and 9F9 by Dr. A. Budzynski (Temple University, Philadelphia, PA). They are anti-RIBS (receptor induced binding site ) $\mathrm{mAbs}$ which recognize determinants expressed when fibrinogen is attached to the GP IIb-IIIa receptor, but not when it is in the soluble phase $(20,21)$. They were used as purified IgG, F26 at $5 \mu \mathrm{g} / \mathrm{ml}$ and 9F9 at $20 \mu \mathrm{g} / \mathrm{ml}$. The methodology used in these experiments was based on that described by Shattil et al. (17). It consisted of adding $10 \mu \mathrm{l}$ of whole blood anticoagulated with sodium citrate (see above) to a second tube containing purified fibrinogen (Kabi AB) at $400 \mu \mathrm{g} / \mathrm{ml}$, an agonist such as $10 \mu \mathrm{M}$ ADP, and $100 \mu \mathrm{l}$ of the mAb directed against activated GP IIb-IIIa or a RIBS epitope. After $15 \mathrm{~min}$, the second antibody, dichlorotriazinylamino fluorescein-conjugated $\mathrm{F}\left(\mathrm{ab} \mathrm{b}^{\prime}\right)_{2}$ fragments of a donkey antibody to mouse IgM (Jackson ImmunoResearch Laboratories, Inc., West Grove, PA) or FITC-labeled $\mathrm{F}\left(\mathrm{ab}^{\prime}\right)_{2}$ fragments of a sheep antibody to mouse IgG (Silenus Laboratories Pty, Ltd.), were added. The samples were incubated for $15 \mathrm{~min}$, diluted, and then analyzed in the flow cytometer. Controls were performed with irrelevant IgM or IgG of the same subclass of each antibody or in the absence of the first antibody. Samples were also regularly examined with a fluorescence microscope (Microphot-FX; Nikon France, Charenton-Le Pont, France) installed with a 100-W mercury lamp. Some later studies with these mAbs were performed using platelets stimulated in citrated PRP as described for the fibrinogen-binding experiments.

Flow cytometry. The initial glycoprotein analysis of (M. L.) platelets was performed using a flow cytometer (Spectrum III; Ortho Diagnostic Systems Inc.) as described by Hourdillé et al. (11). The binding of fibrinogen and the activation-dependent mAbs for GP IIb-IIIa were subsequently assessed using a FACScan ${ }^{\circledR}$ (Becton Dickinson France S.A., Le Pont de Claix, France) equipped with a $70-\mu \mathrm{m}$ aperture and a laser argon-ion lamp (emission $488 \mathrm{~nm}$ ). Here, the pressure of $4.5 \mathrm{psi}$ was reduced to 3.9 psi to avoid the overlapping of platelets during their passage across the laser beam (conditions determined with Mr. Sylvain Tallet from Becton Dickinson France S.A., Paris). The samples were first analyzed by forward and wide angle light scatter and the gates set so as to include the majority of the platelets. The fluorescence was measured after passage through a 530-nm long pass interference filter.
Histograms were obtained from 10,000 cells and data was analyzed using the Lysys II software.

\section{Single- and two-dimensional electrophoresis of platelet proteins}

Washed platelets from patient (M. L.), the Glanzmann's patient (F. La.), and three controls were analyzed by single- and two-dimensional electrophoresis as described by Nurden et al. (22). Samples (200 $\mu \mathrm{g}$ protein) were also made $9 \mathrm{M}$ with urea and $8 \%$ ( $\mathrm{vol} / \mathrm{vol}$ ) with NP40. Two-dimensional electrophoresis of platelet proteins was performed according to O'Farrell et al. (23) as adapted by Hanash et al. (24). Briefly, isoelectrofocusing of proteins on $4 \%$ rod gels was performed in the presence of NP-40, SDS, urea, $\beta$-mercaptoethanol, and ampholines (Pharmacia LKB Biotechnology Inc.). The second dimension migration was performed using a 7-20\% polyacrylamide gradient gel under reducing conditions. Proteins were detected by silver staining.

\section{Sample preparations for electron microscopy and immunogold staining}

Standard transmission electron microscopy was performed as described by Hourdillé et al. (11). Sections of aggregates were analyzed as follows: platelets in citrated PRP were stirred in the platelet aggregometer at $37^{\circ} \mathrm{C}$ in the presence of $10 \mu \mathrm{M} \mathrm{ADP}$ and fixed at the peak of the aggregation response by adding the contents of the cuvette to $1.25 \%$ (wt/ vol) glutaraldehyde (Fluka Chemie AG, Buchs, Switzerland) diluted in $0.1 \mathrm{M}$ phosphate buffer, $\mathrm{pH}$ 7.3. The remaining steps were based on procedures previously described by Heilmann et al. (25). In brief, samples were preembedded in low-gelling temperature agarose and dehydrated through a series of graded alcohols at $-20^{\circ} \mathrm{C}$ before being embedded in Lowicryl K4M (Taab, Aldermaston, United Kingdom). After photopolymerization, blocks were cut using an Ultracut E Ultramicrotome (Reichert Jung, Vienna, Austria) and ultrathin sections mounted on colloidium-coated nickel grids. Labeling of fibrinogen was performed by sequentially incubating the sections with the IgG of a commercial polyclonal rabbit antifibrinogen antibody ( $100 \mu \mathrm{g} / \mathrm{ml}$; Dakopatts) followed by a goat anti-rabbit IgG antibody conjugated to 5-nm gold particles ( $1 / 70$ dilution, Auroprobe EM GAR G5; Janssen Pharmaceutica, Beerse, Belgium). A negative control was obtained with normal goat serum. Sections were observed at $60 \mathrm{kV}$ in an EM 201 electron microscope (Phillips Co., Ltd., Eindoven, The Netherlands).

\section{Other methods}

Platelet nucleotides were measured using the luciferin luciferase procedure as previously employed by us (26). In this procedure, ADP is converted into ATP by pyruvate kinase in the presence of phosphoenolpyruvate. ATP is then quantitated by measuring the amount of light emitted by luciferin luciferase extracts in a bioluminometer (1250; Pharmacia LKB Biotechnology Inc.). The mepacrine test was performed using PRP prepared from blood taken into acid-citrate-dextrose NIH formula A (26). In brief, aliquots ( $500 \mu \mathrm{l})$ of PRP were incubated with $50 \mu \mathrm{M}$ mepacrine (DL-quinacrine $\mathrm{HCl}$; ICN Flow Laboratories, Orsay, France) for $10 \mathrm{~min}$ at $37^{\circ} \mathrm{C}$ and the platelets washed in Tyrode's buffer, pH 6.5, before being resuspended in PBS and examined in a Nikon Microphot-FX fluorescence microscope (see above). Platelet volume was measured in a Coulter counter (Coultronics, Paris, France), for (M. L.) it was $7.47 \mathrm{fl}$, well within the normal range for our laboratory.

\section{Results}

\section{Platelet morphology and dense granule content}

Standard transmission electron microscopy confirmed that unstimulated (M. L.) platelets had a usual discoid form, and that the $\alpha$-granules and other organelles, including the surface-connected canalicular system, were normally present. Dense granules in (M. L.) platelets were visualized in a fluorescence microscope after mepacrine labeling and had a usual appearance. 

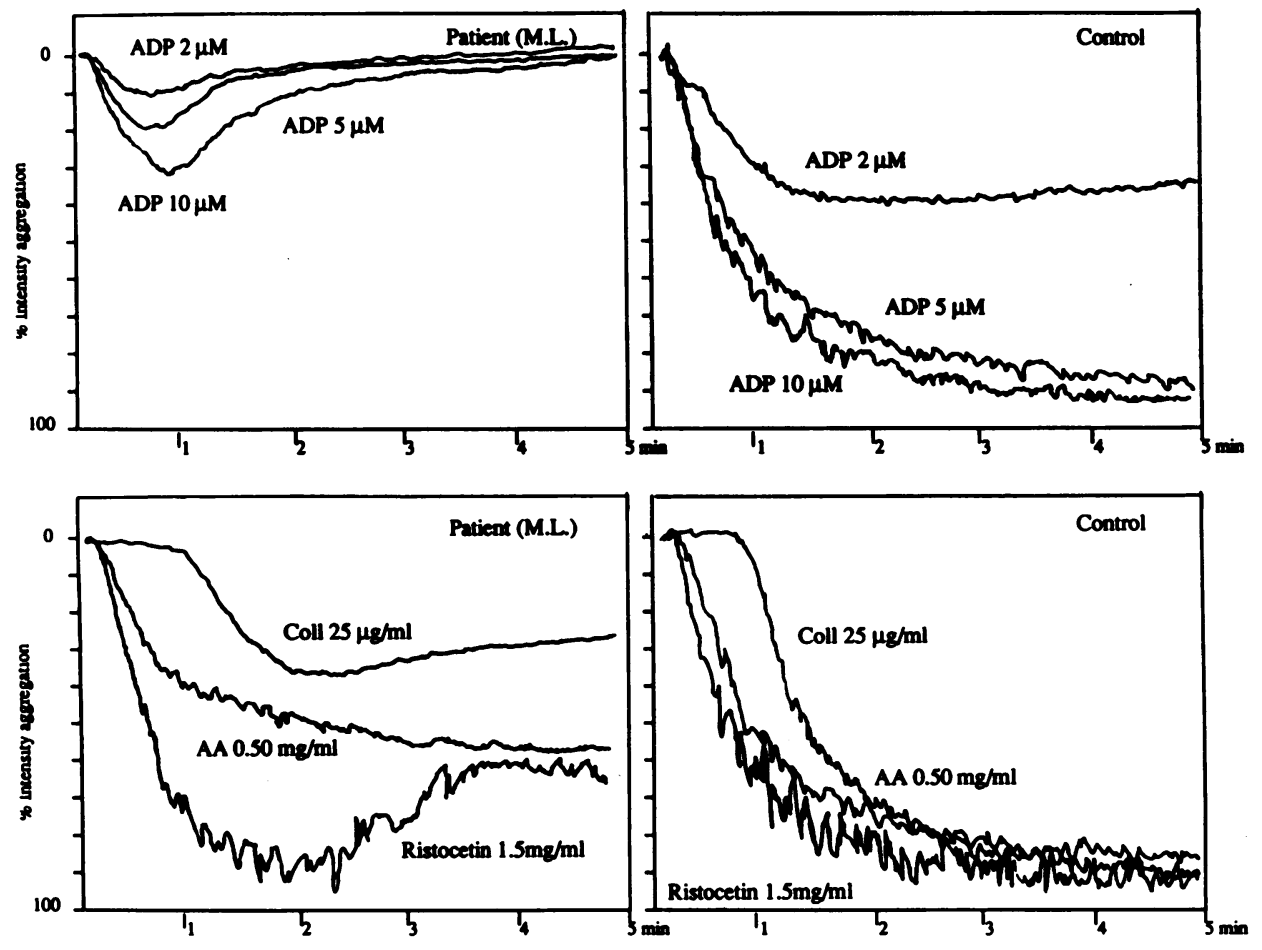

Figure 1. Platelet aggregation patterns for the patient $(M . L$.$) as compared$ with a control donor. Platelets adjusted to $2.5 \times 10^{8} / \mathrm{ml}$ in citrated PRP were stimulated with 2,5 , and $10 \mu \mathrm{M}$ ADP, $25 \mu \mathrm{g} / \mathrm{ml}$ collagen (Coll), 0.50 $\mathrm{mg} / \mathrm{ml} \mathrm{AA}$, and $1.5 \mathrm{mg} / \mathrm{ml}$ ristocetin as shown. Results for the patient are typical of those obtained on at least three occasions.

Counting revealed an average of 5.4 granules/platelet, which was normal for our laboratory. The nucleotide content of (M. L.) platelets was $8.69 \mu \mathrm{mol} / 10^{11}$ platelets for ATP and $4.50 \mu \mathrm{mol} / 10^{11}$ platelets for ADP (normal values: $6.98 \pm 1.31$ $\mu \mathrm{mol} / 10^{11}$ platelets for ATP and $3.32 \pm 1.24 \mu \mathrm{mol} / 10^{11}$ platelets for ADP). Electron microscopy showed that when challenged with ADP or other agonists, unstirred suspensions of the patient's platelets responded by changing shape and forming pseudopods (illustrated for ADP in Fig. 8).

\section{Platelet aggregation}

Function testing has been performed on platelets from (M. L.) on many occasions, beginning in 1975. Typical results for citrated PRP are illustrated in Fig. 1. ADP $(2-10 \mu \mathrm{M})$ induced a limited and always reversible aggregation whatever the dose used. Even with $50 \mu \mathrm{M}$ ADP, the response does not increase and remains reversible (not illustrated). Under identical conditions, the aggregation response of normal platelets to doses of $5 \mu \mathrm{M}$ or more ADP is irreversible and of much higher intensity. For a series of 10 normal donors tested recently in our laboratory, the maximal intensity of aggregation with $5 \mu \mathrm{M}$ ADP reached $83.3 \pm 7.5 \%$. The aggregation of $(M$. L.) platelets with $500 \mu \mathrm{g} / \mathrm{ml}$ arachidonic acid was irreversible and normal. With 25 and $50 \mu \mathrm{g}$ collagen, the aggregation of the patient's platelets over the years was variable. On some occasions it appeared normal and at other times the lag phase at the lower dose was longer and the intensity reduced compared with the control (as illustrated in Fig. 1). With $25 \mu \mathrm{g} / \mathrm{ml}$ collagen, the maximal intensity for a series of 10 normal donors was $80.3 \pm 8.78 \%$. We suspect that the increased lag phase may reflect a reduced contribution of ADP to the aggregation response of the patient's platelets to this dose of collagen (see Discussion). Incubation of (M. L.) platelets with ristocetin in citrated PRP resulted in a normal initial agglutination (Fig. 1). However, if the aggrego- meter recorder was allowed to continue, waves of agglutination and disagglutination were observed, each wave lasting about 4 $\min$. This type of response to ristocetin has previously been reported in Glanzmann's thrombasthenia (see reference 6). High concentrations of TRAP-14-mer induced a rapid aggregation of (M. L.) platelets with a normal maximum intensity in citrated PRP (Fig. 2). With lower amounts of this peptide the response of the patient's platelets was again somewhat reduced when compared with the control. Washed (M. L.) platelets aggregated normally (not illustrated), secreted, and showed the usual surface expression of P-selectin when challenged with 0.5 $\mathrm{U} / \mathrm{ml} \alpha$-thrombin (Table I). This latter observation confirmed that thrombin was able to induce secretion, a finding also observed with high doses of TRAP-14-mer peptide (not illustrated). A normal aggregation was seen when washed control platelets were resuspended in the patient's platelet-poor plasma before being challenged with $10 \mu \mathrm{M}$ ADP (data not shown).

Citrated PRP from the patient's daughter (C. L.) and sister (Ma-L.) have, at various times, both been tested in aggregation. The response for (Ma-L.) was typical of that illustrated here, with a small and reversible aggregation even at high doses of ADP. In contrast, platelets from (C. L.), while barely responding to 1 and $2 \mu \mathrm{M}$ ADP, gave a normal irreversible aggregation with $10 \mu \mathrm{M}$ ADP (data not shown).

\section{Effect of ADP on cAMP levels of PGE platelets}

It was important to determine whether the patient's defect concerned a pathway specific for platelet activation with ADP. The ability of ADP to lower $\mathrm{PGE}_{1}$-induced cAMP levels in normal platelets is well documented. Fig. 3 shows that $\mathrm{PGE}_{1}$ induced a four- to fivefold increase in the levels of cAMP in the platelets of (M. L.). Platelets from a patient with type I Glanzmann's thrombasthenia (F. La.) were incubated in parallel and also 

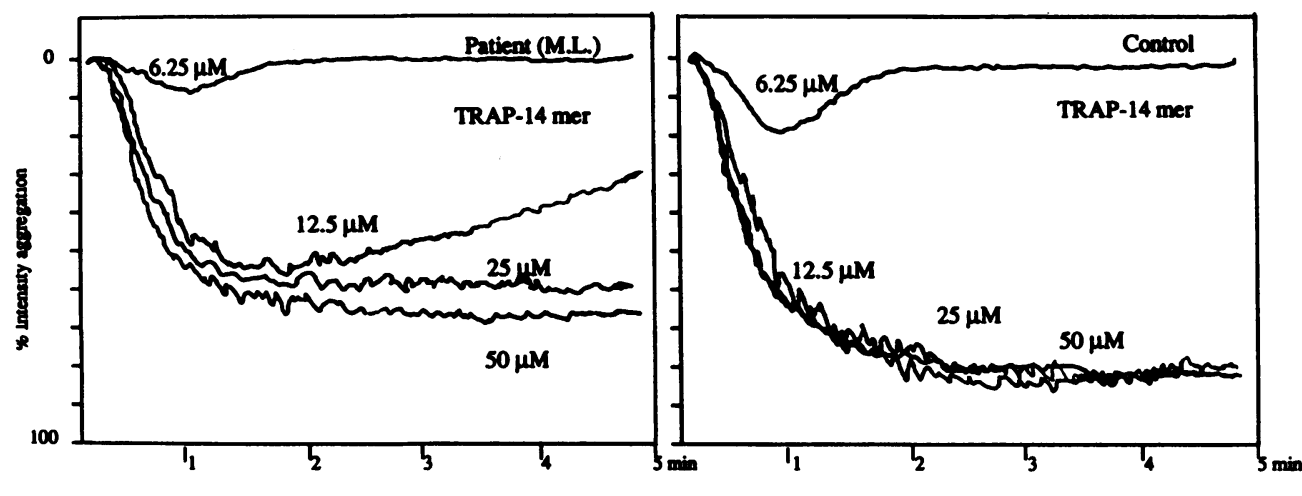

Figure 2. The aggregation of platelets from the patient $(M . L$. or a control donor with the TRAP14 mer peptide. Platelets adjusted to $2.5 \times 10^{8} / \mathrm{ml}$ in citrated PRP were stimulated with $6.25-50 \mu \mathrm{M}$ TRAP-14 mer peptide as shown. responded normally. After this initial increase, the amounts of cAMP remained relatively constant for the incubation period which followed. However, addition of epinephrine or ADP to $\mathrm{PGE}_{1}$-stimulated normal platelets was followed by $\sim 50 \%$ decrease in the platelet cAMP level during a 15-min period. Such results are similar to those previously reported by others (27, 28). Fig. 3 shows that platelets of both (M. L.) and (F. La.) gave a normal response to epinephrine. In contrast, (M. L.) platelets totally failed to respond to ADP, whereas those of the Glanzmann's patient reacted with a fall similar to that seen in the controls. Finally, it should be noted that the baseline level of cAMP in unstimulated (M. L.) platelets was also normal.

\section{Analysis of the binding of $\left[{ }^{3} \mathrm{H}\right] 2-\mathrm{MeS}-\mathrm{ADP}$ to platelets}

As first shown by others $(29,30)$, the specific binding of 2 MeS-ADP to washed normal human platelets was dose dependent and saturable, reaching a maximum at $\sim 10 \mathrm{nM}$ of the agonist (Fig. 4). Nonlinear regression and Scatchard analyses revealed the presence of a single class of high affinity binding sites with an apparent equilibrium dissociation constant $\left(K_{\mathrm{d}}\right)$ of $2.16 \pm 0.79 \mathrm{nM}$. This represented the binding of $138.8 \pm 21.0$ fmol $/ 10^{8}$ platelets or $836 \pm 126$ molecules/platelet $(n=3)$. Significantly, $\left[{ }^{3} \mathrm{H}\right] 2-\mathrm{MeS}-\mathrm{ADP}$ bound normally to platelets from the Glanzmann's thrombasthenia patient (F. La.) (Fig. 4), ruling out a role for GP IIb-IIIa complexes in the binding of this derivative of ADP. In contrast, platelets from (M. L.) bound $30 \pm 17$ molecules of $\left({ }^{3} \mathrm{H}\right)-2-\mathrm{MeS}-\mathrm{ADP}$, this represented a $96 \%$

Table I. mAb Binding in Flow Cytometry

\begin{tabular}{clclc}
\hline & \multicolumn{2}{c}{ Mean fluorescence intensity (arbitrary units) } \\
\cline { 2 - 5 } mAbs & \multicolumn{2}{c}{$\begin{array}{c}\text { Unstimulated } \\
\text { platelets }\end{array}$} & \multicolumn{2}{c}{$\begin{array}{c}\text { Platelets stimulated with } \\
0.5 \text { U/ml thrombin }\end{array}$} \\
\hline GP IIb-IIIa & M.L. & 145 & M.L. & 155 \\
(AP-2) & Control & $120 \pm 19.8$ & Control & $159 \pm 14.3$ \\
GP Ib & M.L. & 140 & M.L. & 102 \\
(Bx-1) & Control & $135 \pm 12.5$ & Control & $101 \pm 10.8$ \\
P-selectin & M.L. & $38 *$ & M.L. & 100 \\
(VH10) & Control & $31 \pm 7.28^{*}$ & Control & $103 \pm 16.9$ \\
& & & & \\
\hline
\end{tabular}

Platelets were incubated with or without thrombin for $10 \mathrm{~min}$ at $37^{\circ} \mathrm{C}$ before fixation with PFA. Incubation with the $\mathrm{mAbs}$ and flow cytometry was performed as in Methods. Results for a typical experiment with (M.L.) are compared with those for 10 controls. * Values largely represented by platelet autofluorescence. decrease in the number of sites compared with control platelets. Despite this decrease, the $K_{\mathrm{d}}$ of the residual [ $\left.{ }^{3} \mathrm{H}\right]$ 2-MeS-ADP binding to (M. L.) platelets was $2.07 \pm 0.25 \mathrm{nM}$, a value that was similar to that observed for this ligand on control platelets. We were also, on one occasion, able to study the patient's daughter. As shown in Fig. 4, her platelets bound intermediate levels of $\left[{ }^{3} \mathrm{H}\right] 2-\mathrm{MeS}-\mathrm{ADP}$. Although substantial, this result suggests that she is heterozygous for the defect while the fact that her platelets respond normally to ADP (and her bleeding time is normal), suggests that this receptor density is sufficient for a full platelet response to ADP.

\section{Flow cytometry experiments}

We first used flow cytometry to examine the glycoprotein content of (M. L.) platelets, and to assess glycoprotein movements when washed platelets were stimulated with a strong agonist such as thrombin. Next, we evaluated the ability of ADP to induce the patient's platelets to bind fibrinogen in citrated PRP. Finally, we analyzed the ADP-dependent expression of activation-dependent epitopes on the GP IIb-IIIla complexes of the abnormal platelets in whole blood or citrated PRP.

Expression of membrane glycoproteins at the platelet surface. mAbs to GP IIb-IIIa complexes (AP-2), or GP Ib (Bx1 ), both bound normally to PFA-fixed (M. L.) platelets. A representative result is shown in Table $I$. This provided initial evidence that the patient did not have a variant form of Glanzmann's thrombasthenia and confirms the results later obtained

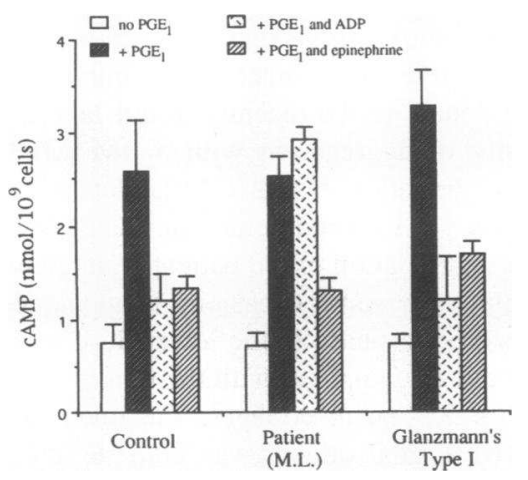

Figure 3. $\mathrm{PGE}_{1}$-induced increase in platelet cAMP levels and its inhibition by ADP and epinephrine. Citrated PRP (adjusted to $2 \times 10^{8} / \mathrm{ml}$ ) from a control donor, patient (M. L.), and the Glanzmann's thrombasthenia patient (F. La.) was incubated for $1 \mathrm{~min}$ at $37^{\circ} \mathrm{C}$ and samples taken to determine the basal level of cAMP. $\mathrm{PGE}_{1}$ was then added and the samples incubated for $3 \mathrm{~min}$ at $37^{\circ} \mathrm{C}$. ADP $(10 \mu \mathrm{M})$, epinephrine $(10 \mu \mathrm{M})$, or buffer was then added and the samples incubated for a further $3 \mathrm{~min}$ at $37^{\circ} \mathrm{C}$. Extracted cAMP was determined using an assay kit. Mean \pm SD, $n=3$. 

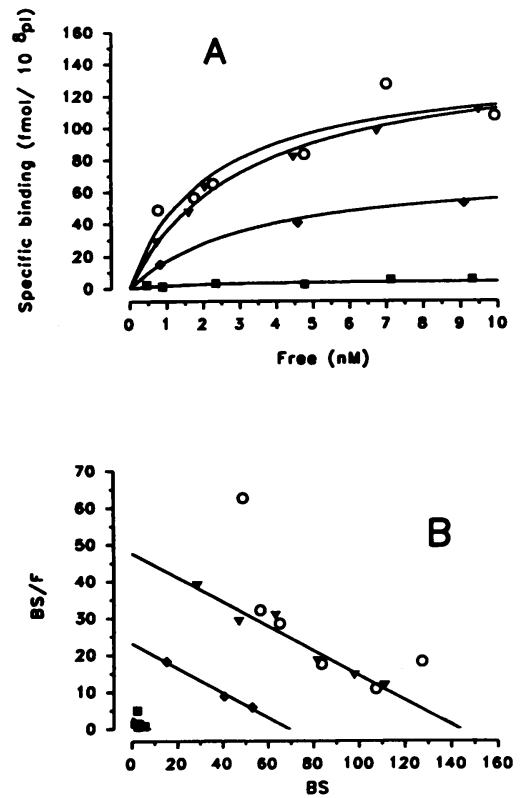

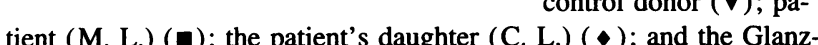
mann's patient (F. La.) (O). $B$ shows the Scatchard representation of the data.

by gel electrophoresis procedures (see below). Furthermore, treatment of (M. L.) platelets with thrombin $(0.5 \mathrm{U} / \mathrm{ml})$ resulted in the usual changes in the organization of these glycoproteins on the platelet surface (Table I). These included $(a)$ an increased expression of GP IIb-IIIa due to the surface exposure of the internal pool, and $(b)$ a decreased expression of GP IbIX complexes.

Binding of fibrinogen to ADP-stimulated platelets. Studies were first performed using citrated PRP. Fig. 5 illustrates the dot blot profiles obtained when platelets from (M. L.) and a control donor were analyzed in the flow cytometer. In the absence of stimulation, the size distribution of platelets from the patient and the control were indistinguishable. Incubation of normal platelets with ADP for $10 \mathrm{~s}$ (the shortest time point studied in our experiments) was sufficient for many of them to bind fibrinogen, the labeled platelets appearing within the upper quadrants of the cytogram. Increasing the incubation time of the platelets with ADP to $1 \mathrm{~min}$ did not result in a major increase in the amount of bound fibrinogen detected by the antifibrinogen antibody. It can also be seen that the size distribution within the normal platelet suspensions changed after the addition of ADP. Examination of the suspensions in a fluorescence microscope confirmed that this was due to the formation of small clusters of platelets. This was despite the only stirring being an initial mixing. As might be expected, the highest intensity of fluorescence was detected within the zone containing the microaggregates.

Results for the patient (M. L.) were quite different. After $10 \mathrm{~s}$ with ADP, only an estimated $5 \%$ of the platelets had bound clearly detectable amounts of fibrinogen and only a few small aggregates had formed (see the top right hand quadrant of Fig. 5). 1 min after the incubation with ADP, some $13 \%$ of the platelets were recognized by the antifibrinogen antibody. Significant numbers of aggregated platelets were not to be seen, and any increases in mean fluorescence intensity were small. For the Glanzmann's patient (F. La.), no binding of fibrinogen was detected even up to $3 \mathrm{~min}$ after the addition of the ADP (data not illustrated). Incubation of normal or (M. L.) platelets with the FITC-labeled second antibody alone, or performing the procedure in the absence of ADP, resulted in no labeling of the platelets. On one occasion, the kinetics of the ADPinduced binding of FITC-labeled fibrinogen to washed control
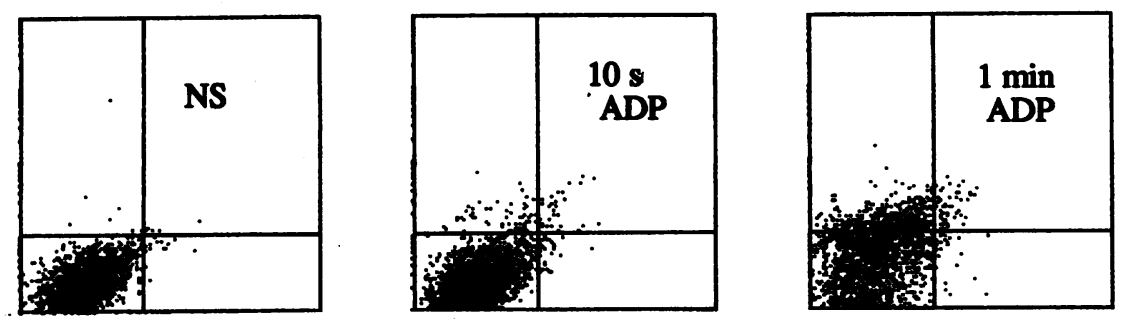

Figure 5. Two parameter flow cytometric analysis of the ADP-induced binding of fibrinogen to platelets in citrated PRP. PRP was Patient incubated in the presence or ab(M.L.) sence of $10 \mu \mathrm{M}$ ADP for $10 \mathrm{~s}$ or $1 \mathrm{~min}$ before the addition of rabbit antifibrinogen antibodies. After 2 min, FITC-conjugated $F\left(a b^{\prime}\right)_{2}$ fragments of a sheep antibody to rabbit IgG were added. $8 \mathrm{~min}$ later the samples were analyzed in the FACScan ${ }^{\otimes}$ (Becton Dickinson Immunocytometry Systems). The fluorescence $(F L 1)$ was plotted against platelet size represented
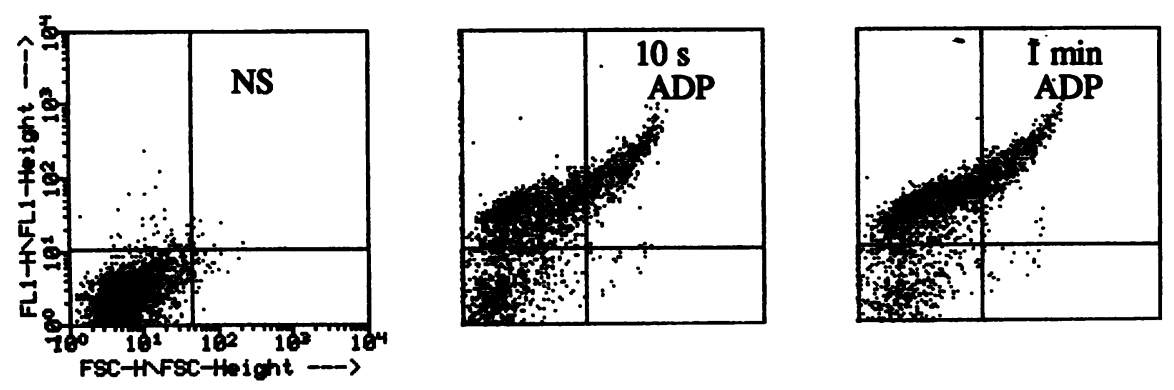

Control by forward light scatter (FSC). After the addition of ADP to the control sample, most of the platelets exhibited fibrinogen binding and an increased fluorescence. This was manifested by the appearance of the platelets in the upper quadrants $(\sim 75 \%$ of the total population). At the same time, a shift to the right ( $20 \%$ of the cells are in the upper right quadrant after 1 min with ADP) corresponds to the formation of microaggregates. For the patient (M. L.), only a small modification was seen after the addition of the ADP. After $10 \mathrm{~s}$, only $5 \%$ of the cells reach the upper quadrants, after $1 \mathrm{~min}$ only $13 \%$ of the cells exhibited increased fluorescence, while only $3 \%$ were in the form of microaggregates. 

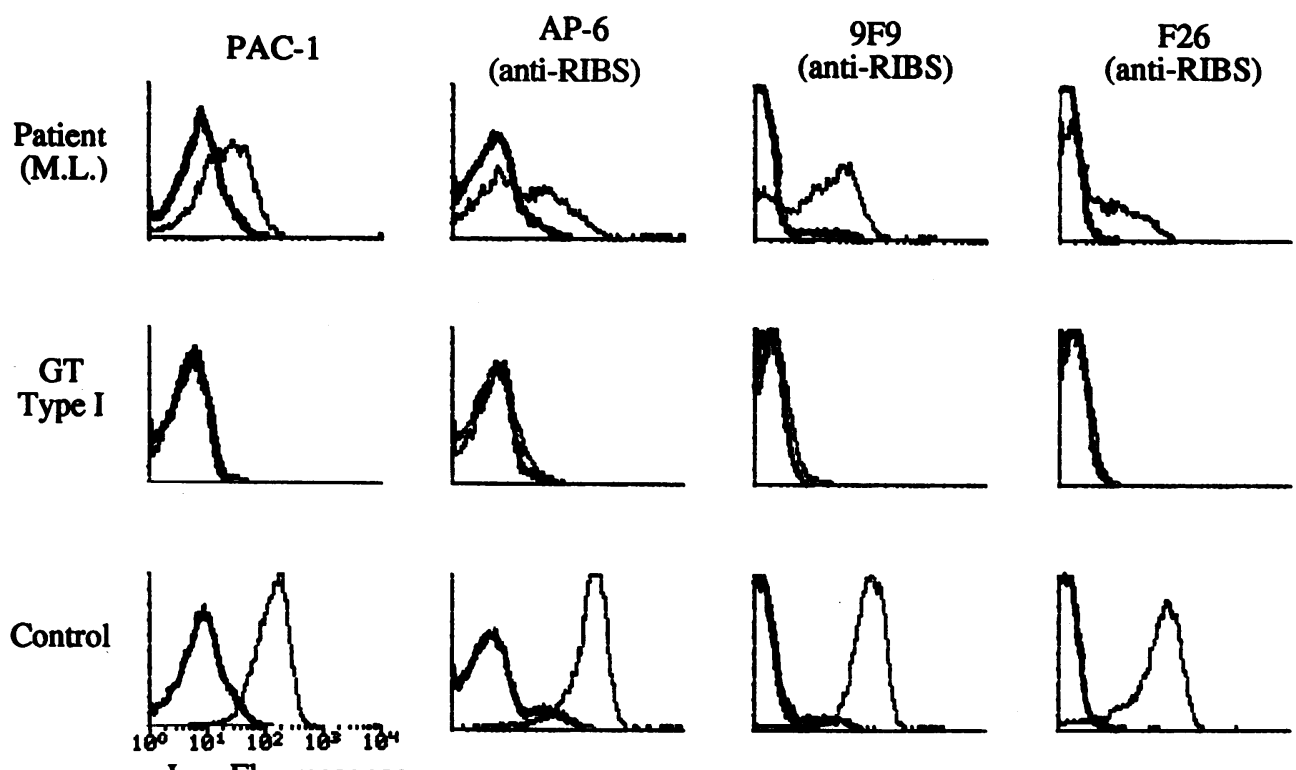

Figure 6. Flow cytometric analysis of activation-dependent markers on GP IIb-IIIa complexes.

Here, citrated whole blood from patient (M. L.), the patient with Glanzmann's thrombasthenia

(F. La.), or a control donor was added to tubes containing fibrinogen ( to give $200 \mu \mathrm{g} / \mathrm{ml}$ ) together with one of the mAbs PAC-1, AP6 , F26, or 9F9. The tubes were incubated for $15 \mathrm{~min}$ in the presence (dashed line) or absence (heavy line) of $10 \mu \mathrm{M}$ ADP. Then, dichlorotriazinylamino fluorescein conjugated $\mathrm{F}\left(\mathrm{ab}^{\prime}\right)_{2}$ fragments of donkey anti-mouse IgM or FITC-labeled $\mathrm{F}\left(\mathrm{ab}^{\prime}\right)_{2}$ fragments of sheep anti-mouse IgG were added and the incubation continued for a further 15 min. Aliquots ( 10,000 cells) were analyzed by flow cytometry. It can be seen that none of the mAbs

bound to the platelets of the Glanzmann's patient (F. La.), with or without ADP. For the patient (M. L.), PAC-1 bound in small amounts after ADP activation and there was a global shift of the histogram to the right. For AP-6, 9F9, and F26, subpopulations of weakly positive platelets could also be discerned for this patient.

and (M. L.) platelets were also studied. A rapid but much reduced binding of fibrinogen to (M. L.) platelets was confirmed with a maximum at $20 \mathrm{~s}$ (data not shown).

Expression of activation-dependent epitopes on the platelet GP IIb-IIIa complex. We next used a panel of four mAbs directed against activation-dependent epitopes on GP IIb-IIIa complexes, or on fibrinogen bound to these complexes, to further evaluate the response of (M. L.) platelets to ADP. To get as close as possible to physiologic conditions, the bulk of these studies were performed using citrated whole blood. Fig. 6 compares the binding of each antibody to $(a)(\mathrm{M}$. L.) platelets, $(b)$ platelets from the Glanzmann's patient (F. La.), and (c) control platelets. Incubations were for $3 \mathrm{~min}$ with or without $10 \mu \mathrm{M}$ ADP. With PAC-1 and AP-6, IgM antibodies binding to activation-dependent epitopes on GP IIb-IIIa, incubation of normal blood with ADP resulted in the detection of a well separated peak containing the bulk of the platelets which were clearly activated. No binding was observed with platelets from the Glanzmann's patient (F. La.). Interestingly, patient (M. L.) gave a partial and weak response, with only a proportion of the platelets being recognized by either AP- 6 or PAC- 1 . The mean fluorescence intensities of the positive subpopulation of (M. L.) platelets for both antibodies were much less than those seen for activated normal platelets. The histograms obtained when unstimulated normal, (M. L.) or (F. La.) platelets were incubated with PAC-1 and AP-6 were virtually superimposable, a result which confirms that there was little or no spontaneous platelet activation under our experimental conditions. Kinetic experiments performed with PAC-1 in citrated PRP showed that the PAC-1 determinant was rapidly expressed on ADPstimulated platelets and remained stable over a $15-\mathrm{min}$ period (data not shown).

Again in whole blood, virtually all ADP-stimulated normal platelets bound 9F9 and F26, IgG mAbs which recognize RIBS epitopes on fibrinogen attached to the GP IIb-IIIa receptor.
The histograms were symmetric and well separated, confirming that appreciable fibrinogen binding had occurred (Fig. 6). In contrast, only a subpopulation of (M. L.) platelets were recognized by the anti-RIBS mAbs, again the mean fluorescence intensities were much less than those observed for the same mAbs with ADP-stimulated normal platelets. The platelets of this patient which bound 9F9 were slightly more positive than those labeled with F26, a finding that may reflect the relative sensitivities of the two antibodies for their RIBS epitopes. ADPstimulated platelets from the Glanzmann's patient were negative for both 9F9 and F26. Globally, these results mirrored those obtained with AP-6 and PAC-1.

Citrated blood from (M. L.) was incubated with D33C, an $\mathrm{mAb}$ whose binding is dependent on the activation of GP IIbIIIa (see Discussion). D33C bound equivalently to control platelets and those from (M. L.) (Fig. 7). This result is important, for it shows that when stimulated directly, the GP IIbIIIa complex on (M. L.) platelets is able to respond normally. Platelets from the Glanzmann's patient failed to bind D33C (result not shown).

\section{Immunogold staining of ADP-induced platelet aggregates}

Experiments were performed to examine the morphology of the aggregates obtained when (M. L.) platelets were stimulated with ADP. Citrated PRP was stirred with $10 \mu \mathrm{M}$ ADP in an aggregometer under identical conditions for the platelet aggregation tests shown in Fig. 1. Samples were fixed at the peak of the aggregation curve and embedded in the resin, Lowicryl $\mathrm{K} 4 \mathrm{M}$. Ultrathin sections were sequentially incubated with a rabbit antibody to fibrinogen followed by an anti-rabbit IgG antibody conjugated to 5-nm gold particles. Fig. 8 shows that aggregates in (M. L.) PRP were composed of a small number of loosely bound platelets with comparatively few contact points. Immunogold staining for fibrinogen showed the occasional surface labeling at and around the contact points. The normal $\alpha$-granule con- 


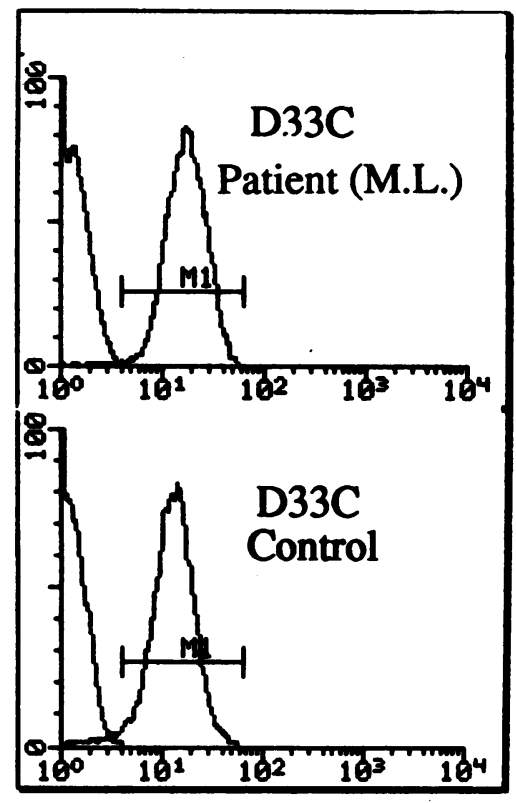

Figure 7. Flow cytometric analysis of the binding of the activating $\mathrm{mAb}$ D33C to control platelets and those from the patient (M. L.). Methods were as described in the legend to Fig. 5. Platelets were incubated with 10 $\mu \mathrm{g} / \mathrm{ml}$ of D33C (histogram $M 1)$ or an irrelevant mouse IgG. As can be seen, the GP IIb-IIIa complexes of (M. L.) platelets and those of platelets from a control donor bound equivalent amounts of antibody.

tent of (M. L.) platelets is confirmed as is the fact that the platelets have responded to ADP. Pseudopods can be clearly identified. The selected illustration is typical of the many sections examined. In contrast, aggregates of normal platelets fixed at the same time point contained many platelets in close contact, a finding previously illustrated by us (see reference 25 ).

\section{Analysis of platelet proteins}

It was important to be certain that (M. L.) platelets did not possess quantitative or qualitative abnormalities of GP IIb-
IIIa complexes. We first compared the protein and glycoprotein patterns of platelets from the patient (M. L.), the Glanzmann's thrombasthenia patient (F. La.), and normal donors using standard single dimension gel electrophoresis procedures as previously used by us (22). While confirming the severe deficiency of GP IIb and GP IIIa in (F. La.) platelets, these procedures showed that the glycoprotein and protein profiles of (M. L.) platelets were indistinguishable from those of the controls (results not shown). We then turned to two-dimensional electrophoresis procedures. Silver staining showed that GP IIb and GP IIIa were normally present in (M. L.) platelets, without modifications of their pI or relative molecular mass (data not illustrated).

\section{Discussion}

Patient (M. L.) has a selective impairment of ADP-induced platelet aggregation. In citrated platelet-rich plasma, his platelets responded to medium and high doses of ADP with a limited but rapid initial aggregation which was followed by an equally quick dissociation of the aggregates. In contrast, medium and high doses of collagen, TRAP-14-mer peptide, and arachidonic acid all gave the usual irreversible aggregation showing that the surface receptors and the signal transmission pathways necessary for these aggregation responses were operative. Analyses of platelet nucleotides and platelet proteins confirmed that the patient did not have storage pool disease, a conclusion reinforced by a normal labeling of dense granules with mepacrine and a usual P-selectin expression in response to thrombin. A family history of bleeding together with occasional studies on platelets from a sister and his daughter, strongly suggested that the platelet abnormality was inherited and is at the origin of the

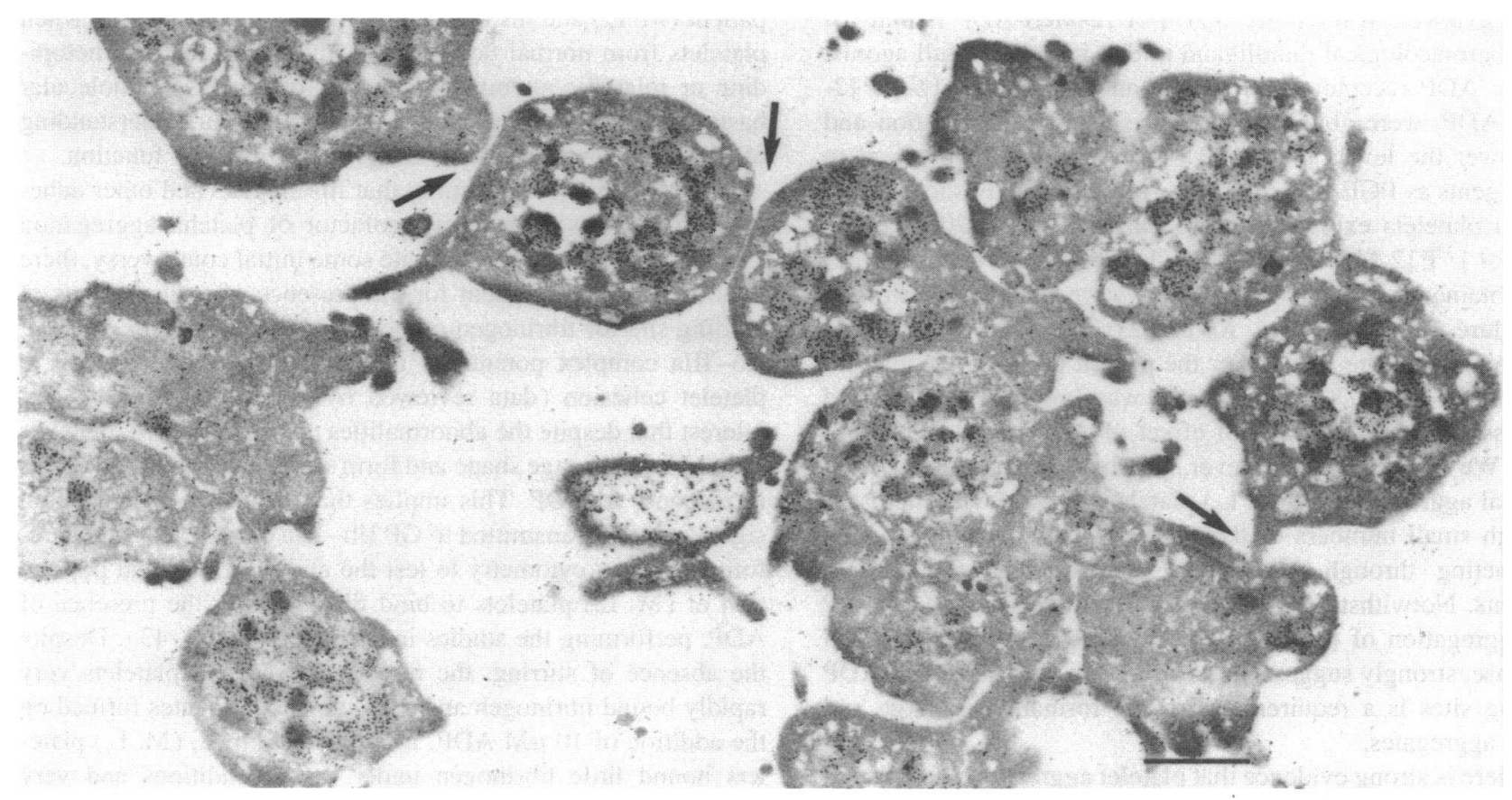

Figure 8. Electron micrograph showing the typical ultrastructure of a platelet aggregate obtained when citrated PRP from the patient (M. L.) was incubated with $10 \mu \mathrm{M}$ ADP in a platelet aggregometer. Samples were fixed at the peak of the aggregation response. Ultrathin sections of samples subsequently embedded in Lowicryl K4M were incubated with rabbit antifibrinogen antibody followed by goat anti-rabbit IgG adsorbed on 5-nm gold particles. The $\alpha$-granule content as visualized by the antifibrinogen antibody confirms that little secretion has occurred. The aggregate contains a small number of loosely bound platelets with few contact points. These images are typical of those seen in many sections. Bar indicates $1 \mu \mathrm{M}$. 
insufficient hemostatic response. Recently, Cattaneo et al. (9) have described an Italian family with a selective abnormality of the platelet response to ADP with similarities to that shown here. These two reports suggest a new type of inherited disorder specific to the ADP-dependent pathway of platelet activation.

Two different experimental approaches provided evidence for an ADP receptor abnormality in (M. L.) platelets. The first involved the selective inability of ADP to lower the level of platelet CAMP after this had been raised by $\mathrm{PGE}_{1}$. The second was the very markedly decreased number of binding sites observed in binding studies with 2-MeS-ADP, a nonhydrolyzable analog of ADP. High, medium, and low affinity binding sites for ADP on platelets have all been described (data reviewed in reference 5). Initially, results with ATP, a competitive and specific antagonist of ADP on platelets, suggested that ADP was acting through a common mechanism (31). Subsequently, studies with $5 '-p$-fluorosulfonylbenzoyl adenosine, an analog with structural similarities to ATP, or with $p$-mercuribenzenesulfonate, appeared to distinguish between the ability of ADP to induce a platelet functional response and its effect on adenylate cyclase (data reviewed in references 4 and 5). Thus the possibility was raised of two distinct populations of receptors for ADP. However, there are doubts that 5-p-fluorosulfonylbenzoyl adenosine fulfills the pharmacological criteria necessary for an ADP receptor antagonist. It is, for example, degraded in plasma to adenosine and may have effects other than at the receptor level (see reference 32 ). The results for the patient (M. L.) strongly suggest that a major defect in the ADP receptor identified through its link to adenylate cyclase can have strong implications for aggregation induced by this agonist. They do not, however, prove that changes in cAMP levels initiate ADP-induced platelet aggregation.

Among the radiolabeled probes that have been synthesized to measure ADP-binding sites on platelets is $\left[{ }^{32} \mathrm{P}\right] 2-\mathrm{MeS}-\mathrm{ADP}$ (data reviewed in reference 30 ). [ $\left.{ }^{32} \mathrm{P}\right] 2-\mathrm{MeS}-\mathrm{ADP}$ is unusual as a pharmacological radioligand in that it acts as a full agonist for the ADP receptor. Both it and another analog, $\left[\beta-{ }^{32} \mathrm{P}\right] 2-$ azido-ADP, were able to $(a)$ induce platelet aggregation and (b) lower the levels of cAMP within platelets preexposed to such agents as $\operatorname{PGE}_{1}(29,33,34)$. An earlier study showed that human platelets express a single class of 400-1,200 binding sites for $\left[{ }^{32} \mathrm{P}\right] 2-\mathrm{MeS}-\mathrm{ADP}$ (29). Our results for normal platelets, obtained using a ${ }^{3} \mathrm{H}$-labeled derivative and a rapid filtration procedure (836 \pm 126 sites, $K_{d} 2.16 \pm 0.79$ ), are very much in agreement with the above. For the patient (M. L.), the number of $\left[{ }^{3} \mathrm{H}\right]-2-\mathrm{MeS}-\mathrm{ADP}$ binding sites was lower by $\sim 96 \%$ and was associated with a lack of effect of ADP on adenylate cyclase. We do not know, however, whether the shape change and residual aggregation of (M. L.) platelets by ADP was mediated through small numbers of the same receptor or whether ADP was acting through a different receptor present in small amounts. Notwithstanding, the fact that at high doses of ADP the aggregation of (M. L.) platelets did not proceed to a full response, strongly suggests that occupancy of the deficient ADP binding sites is a requirement for the formation of large and stable aggregates.

There is strong evidence that platelet aggregation as induced by low doses of agonists such as collagen, arachidonic acid, or thrombin is potentiated by ADP. ADP scavengers such as apyrase or the creatine phosphate/creatine phosphokinase (CP/ $\mathrm{CPK}$ ) system, or inhibitors of ADP binding to platelets such as ATP, reduce the platelet response (data reviewed in reference
9). A similar effect has recently been seen with CP/CPK on aggregation induced by low amounts of TRAP-14-mer peptide (13). An inherited defect in the ADP-dependent pathway of platelet aggregation might also result in a lower than normal sensitivity of platelets to agonists other than ADP, and this was the case for (M. L.). Interestingly, while we did not examine the effect of CP/CPK (or apyrase) on the functional response of (M. L.) platelets to different agonists, Cattaneo et al. (9) did so for their patient where ADP also induced a small and rapidly reversible platelet aggregation at high doses and failed to lower the cAMP levels of platelets preincubated with $\mathrm{PGE}_{1}$. These authors showed that the functional responses of their patient's platelets were very similar to that of normal platelets incubated with $\mathrm{CP} / \mathrm{CPK}$.

Studies by Born and his colleagues first showed that infusing ADP receptor antagonists and ADP-utilizing enzyme systems led to significant increases in the bleeding time in the rat $(35$, 36). More recently, Yao et al. (37) examined the effect of ADP scavengers on platelet aggregation and cyclic flow variations in an experimental canine model, where blood was circulated over stenosed and endothelium-injured coronary arteries. Here, ADP may be released by activated platelets from their dense granules (see reference 7), from damaged vascular or other blood cells, or be metabolized from ATP released from these cells. Apyrase completely abolished cyclic flow variations in $\sim 80 \%$ of cases. Thus, these studies imply that ADP is indeed an important mediator of platelet aggregation and arterial thrombosis in vivo. Yao et al. (37) also studied the effect of clopidogrel, a new generation ticlopidine-like drug, and this proved to be an even more powerful inhibitor of the cyclic flow variations. Clopidogrel, like ticlopidine, is a selective inhibitor of platelet aggregation by $\operatorname{ADP}(38,39)$. Interestingly, both ticlopidine and clopidogrel also neutralize ADP-induced inhibition of $\mathrm{PGE}_{1}$-activated adenylate cyclase $(39,40)$. Thus, the platelet defect in patient (M. L.) and his family closely resembles that seen when platelets from normal donors are under treatment with ticlopidine or related compounds. The elucidation of the molecular basis of the effected pathway(s) may help our understanding of how these antithrombotic drugs inhibit platelet function.

Evidence is overwhelming that fibrinogen (and other adhesive proteins) is an essential cofactor of platelet aggregation (see references 1 and 2). Despite some initial controversy, there is now general agreement for the presence of a single class of binding site for fibrinogen on activated platelets, with each GP IIb-IIIa complex potentially able to participate in platelet to platelet cohesion (data reviewed by Peerschke, 41). It is of interest that despite the abnormalities discussed above, platelets from (M. L.) change shape and form small reversible aggregates in response to ADP. This implies that at least a limited initial signal is being transmitted to GP IIb-IIIa complexes. We therefore used flow cytometry to test the ability of the total population of (M. L.) platelets to bind fibrinogen in the presence of ADP, performing the studies in citrated PRP $(42,43)$. Despite the absence of stirring, the majority of normal platelets very rapidly bound fibrinogen and some small aggregates formed on the addition of $10 \mu \mathrm{M}$ ADP. In marked contrast, (M. L.) platelets bound little fibrinogen under these conditions and very few aggregates were seen. Preliminary studies performed using FITC-labeled fibrinogen suggested a small peak of fibrinogen binding to (M. L.) platelets within 1 min of the addition of the ADP. Significantly, similar results have been reported for normal platelets stimulated in the presence of the ADP scavenger 
enzyme, apyrase (data reviewed in reference 41). We underline that our results with (M. L.) platelets suggests that occupancy of the receptor normally recognized by 2-MeS-ADP is essential for normal fibrinogen binding and the formation of stable aggregates by ADP.

Binding of mAbs to activation-dependent epitopes on GP $\mathrm{IIb}-\mathrm{III}$ or bound fibrinogen was then performed as a measure of platelet activation in whole blood. The $\mathrm{mAbs}$ included PAC1 , which binds close to a fibrinogen-binding site on GP IIbIIIa (see reference 44), AP-6 which binds to a determinant within the $\beta_{3(211-221)}$ sequence (18), and two anti-RIBS mAbs (F26 and 9F9) that recognize epitopes on fibrinogen after it has bound to GP IIb-IIIa $(20,21,45)$. The fact that the mAbs were added before the ADP, meant that their binding reflected the total activation that occurred. Significantly, ADP (10 $\mu \mathrm{M})$ induced only a low expression of the activation epitopes on GP IIb-IIIa within a subpopulation of (M. L.) platelets. In contrast, the mAb D33C, which activates GP III -IIIa complexes directly (19), bound normally to all (M. L.) platelets, again emphasizing the lack of a generalized defect. Thus, the distinctive aggregation response of (M. L.) platelets was directly linked to the limited ability of ADP to turn GP IIb-IIIa on. This was confirmed by electron microscopy and immunogold staining of ADP-induced aggregates of (M. L.) platelets, experiments performed using preparations fixed when the aggregometer tracing was at its maximum. Results clearly showed how the aggregates had a characteristic morphology and consisted of a small number of loosely bound platelets with few contact points. Nonetheless, it was clearly apparent that ADP retained the ability to induce pseudopod formation. Thus, this again points to a selective defect in the interaction between ADP and (M. L.) platelets. Immunogold staining for fibrinogen also confirmed that secretion from $\alpha$-granules had not occurred. As secretion normally precedes irreversible aggregation with medium to high dose ADP in citrated PRP, its absence for (M. L.) may be a direct consequence of the limited platelet to platelet contact in the aggregation response.

Much debate has centered over the identity of the functional ADP-binding proteins on platelets. GP IIb-IIIa complexes were directly implicated when Greco et al. (46) described that adenosine $5^{\prime}-O$-(thiotriphosphate), a potent inhibitor of ADP-induced platelet shape change and aggregation, binds to GP IIb. For this reason, platelets from a patient belonging to the type I subgroup of Glanzmann's disease were examined in parallel throughout our study. These studies were also performed in view of the fact that (M. L.) platelets gave a cyclical response when citrated PRP was incubated with ristocetin, a phenomenon previously observed for patients with Glanzmann's thrombasthenia (47). We interpret these findings as meaning that ADP, released during the initial agglutination induced by ristocetin, normally interacts with its receptor to stimulate fibrinogen binding to GP IIb-IIIa complexes and that the absence (or nonfunctioning) of either receptor can lead to unstable aggregates. We found that ( $a$ ) ADP normally lowered the levels of cAMP raised after the incubation of thrombasthenic platelets with $\mathrm{PGE}_{1}$ and (b) $\left[{ }^{3} \mathrm{H}\right]-2-M e S-A D P$ bound to thrombasthenic platelets in usual amounts and with a comparable affinity (data not shown). We also obtained no evidence for a quantitative or qualitative deficiency of GP IIb-IIIa complexes in (M. L.) platelets. If GP IIb is able to bind ADP, it would appear not to be the receptor deficient in the platelets of patient (M. L.). A second and highly plausible candidate is a $43-\mathrm{kD}$ protein detected by photoaffinity labeling by Cristalli and Mills (48) using a specially modified analog of ADP that competitively inhibited the binding of 2MeS-ADP and which may represent the receptor through which ADP inhibits adenylate cyclase. Similar labeling studies are planned to evaluate the presence on (M. L.) platelets of this protein, which may not be sufficiently abundant to be detected by the electrophoresis procedures so far used by us.

Gachet et al. (49) showed that the addition of either ADP or 2-MeS-ADP increased the binding of a labeled GTP analog to isolated platelet membranes by two- or threefold. This result was interpreted as showing that platelet ADP receptors interact with and activate $G$ proteins. The functional defects in (M. L.) platelets could result from $(a)$ a deficient or a qualitatively abnormal receptor, or (b) a permanently downregulated "nonfunctional" protein. A desensitized receptor could involve an abnormal interaction with a $G$ protein. Alternatively, this could concern a defective kinase or phosphatase enzyme for phosphorylation and dephosphorylation reactions often regulate receptor function (see references 50 and 51). Patients such as (M. L.) are of major interest in view of the selective nature of the defect and the fact that a severe abnormality in 2-MeS-ADP binding results in a limited and reversible ADP-induced platelet aggregation which in turn results in a prolonged bleeding time. This is one of the first pieces of pathophysiological evidence for the importance of ADP in the hemostatic response.

\section{Acknowledgments}

Special help from Robert Combrié who provided excellent technical assistance during some of the platelet studies, is acknowledged.

The authors also thank the Centre National de la Recherche Scientifique, the University of Bordeaux II, Caisse Régionale d'Assurance Maladie d'Aquitaine/Institut National de la Sante et de la Recherche Medicale, the Conseil Régional de l'Aquitaine, the Centre Hospitalier Régional de Bordeaux, and Sanofi Recherche for providing financial support for their work.

\section{References}

1. Kieffer, N., and D. R. Phillips. 1990. Platelet membrane glycoproteins: functions in cellular interactions. Annu. Rev. Cell Biol. 6:329-357.

2. Nurden, A. T., and P. Nurden. 1993. A review of the role of platelet membrane glycoproteins in the platelet-vessel wall interaction. Ballière's Clinical Haematology. 6:653-690.

3. Born, G. V. R. 1962. Aggregation of blood platelets by adenosine diphosphate and its reversal. Nature (Lond.). 194:927-929.

4. Colman, R. W. 1990. Aggregin: a platelet ADP receptor that mediates activation. FASEB (Fed. Am. Soc. Exp. Biol.) J. 4:1425-1435.

5. Gachet, C., and J. P. Cazenave. 1991. ADP induced blood platelet activation: a review. Nouv. Rev. Fr. Hematol. 33:347-358.

6. George, J. N., A. T. Nurden, and D. R. Phillips. 1984. Molecular defects in interactions of platelets with the vessel wall. N. Engl. J. Med. 311:1084-1098.

7. Weiss, H. J. 1987. Inherited disorders of platelet secretion. In Hemostasis and Thrombosis. Basic Principles and Clinical Practice, Second Edition. R. W. Colman, J. Hirsh, V. J. Marder, and E. W. Salzman, editors. J. B. Lippincott Co., Hagerstown, MD. 741-759.

8. George, J. N., A. T. Nurden, and J. P. Caen. 1990. Glanzmann's thrombasthenia: the spectrum of clinical disease. Blood. 75:1383-1395.

9. Cattaneo, M., A. Lecchi, A. M. Randi, J. L. McGregor, and P. M. Mannucci. 1992. Identification of a new congenital defect of platelet function characterized by severe impairment of platelet responses to adenosine diphosphate. Blood. 80:2787-2796.

10. Vu, T.-K., D. T. Hung, V. I. Wheaton, and S. R. Coughlin. 1991. Molecular cloning of a functional thrombin receptor reveals a novel proteolytic mechanism of receptor activation. Cell. 64:1057-1068.

11. Hourdillé, P., E. Heilmann, R. Combrié, and A. T. Nurden. 1990. Thrombin induces a rapid redistribution of glycoprotein Ib-IX complexes within the membrane systems of activated platelets. Blood. 76:1503-1513.

12. Munson, P. V., and D. Rodbar. 1980. Ligand: a versatile computerized 
approach for characterization of ligand-binding systems. Anal. Biochem. 107:220239.

13. Savi, P., F. Dol, and J. M. Herbert. 1993. ADP-dependence of platelet activation induced by a thrombin receptor agonist. Nouv. Rev. Fr. Hematol. 35:115-119.

14. Mears, H., H. F. Kauffmann, G. Koeter, and K. Devries. 1980. Extraction of cyclic AMP for the determination in the competitive protein binding assay. Clin. Chim. Acta. 106:91-97.

15. Pidard, D., R. R. Montgomery, J. S. Bennett, and T. J. Kunicki. 1983 Interaction of AP-2, a monoclonal antibody specific for the human platelet glycoprotein IIb-IIIa complex, with intact platelets. J. Biol. Chem. 258:12582-12586.

16. Shattil, S. J., J. A. Hoxie, M. Cunningham, and L. F. Brass. 1985. Changes in the membrane glycoprotein IIb-IIIa complex during platelet activation. J. Biol. Chem. 260:11107-11114.

17. Shattil, S. J., M. Cunningham, and J. A. Hoxie. 1987. Detection of activated platelets in whole blood using activation-dependent monoclonal antibodies and flow cytometry. Blood. 70:307-315.

18. Piotrowicz, R. S., and T. J. Kunicki. 1990. Identification of an activation dependent epitope on platelet glycoprotein IIIa. J. Cell Biol. 111:403a. (Abstr.)

19. Gulino, D., J.-J. Ryckewart, A. Andrieux, M.-J. Rabiet, and G. Marguerie. 1990. Identification of a monoclonal antibody against GP IIb that interacts with a calcium-binding site and induces aggregation. J. Biol. Chem. 265:9575-9581.

20. Gralnick, H. R., S. B. Williams, L. McKeown, B. Shafer, G. D. Connaghan, K. Hansmann, M. Vail, and L. Magruder. 1992. Endogenous platelet fibrinogen its modulation after surface expression is related to size-selective access to and conformational changes in bound fibrinogen. Br. J. Haematol. 80:347-357.

21. Zamarron, C., M. H. Ginsberg, and E. F. Plow. 1991. A receptor-induced binding site in fibrinogen elicited by its interaction with platelet membrane glycoprotein IIb/IIIa. J. Biol. Chem. 266:16193-16199.

22. Nurden, A. T., D. Dupuis, T. J. Kunicki, and J. P. Caen. 1981. Analysis of the glycoprotein and protein composition of Bernard-Soulier platelets by single and two-dimensional sodium dodecyl sulfate-polyacrylamide gel electrophoresis. J. Clin. Invest. 67:1431-1440.

23. O'Farrell, P. H. 1975. High resolution two-dimensional electrophoresis of proteins. J. Biol. Chem. 250:40007-40015.

24. Hanash, S. M., J. V. Neel, L. J. Baier, B. B. Rosenblum, W. Niezgoda, and D. Markel. 1986. Genetic analysis of thirty-three platelet polypeptides detected in two-dimensional polyacrylamide gels. Am. J. Hum. Genet. 38:352-360.

25. Heilmann, E., P. Hourdillé, A. Pruvost, A. Paponneau, and A. T. Nurden 1991. Thrombin-induced platelet aggregates have a dynamic structure: time-dependent redistribution of GP IIb-IIIa complexes and secreted adhesive proteins. Arterioscler. Thromb. 11:704-718.

26. Hourdillé, P., P. Bernard, F. Belloc, A. Pradet, R. Sanchez, and M. R. Boisseau. 1981. Platelet abnormalities in thermal injury. Study of platelet dense bodies stained with mepacrine. Haemostasis. 10:141-152.

27. Haslam, R. J. 1973. Interaction of the pharmacological receptors of blood platelets with adenylate cyclase. Semin. Hematol. 6:333-350.

28. Simmons, W. F., P. K. Goldsmith, J. Codina, and C. G. Unson. 1989. Gi $_{2}$ mediates $\alpha 2$-adrenergic inhibition of adenylyl cyclase in platelet membranes: in situ identification with $\mathrm{G} \alpha$ C-terminal antibodies. Proc. Natl. Acad. Sci. USA. 86:7809-7813

29. Macfarlane, D., P. C. Srivastava, and D. C. B. Mills. 1983. 2-Methylthioadenosine $\left(\beta-{ }^{32} \mathrm{P}\right)$ diphosphate. An agonist and radioligand for the receptor that inhibits the accumulation of cyclic AMP in intact blood platelets. J. Clin. Invest. 71:420-428.

30. Macfarlane, D. 1992. 2-methylthioadenosine ( $\beta$-32P) diphosphate: synthesis and use as probe of platelet ADP receptors. Methods Enzymol. 215:137-142.

31. Macfarlane, D. E., and D. C. B. Mills. 1974. The effect of ATP on platelets: evidence against the central role of released ADP in primary aggregation. Blood. 46:309-320.

32. Mills, D. C. B., W. R. Figures, L. M. Scearce, G. J. Stewart, R. F. Colman, and R. W. Colman. 1985. Two mechanisms for inhibition of ADP-induced platelet shape change by $5^{\prime}$-p-fluorosulfonylbenzoyladenosine. Conversion to adenosine, and covalent modification at an ADP binding site distinct from that which inhibits adenylate cyclase. J. Biol. Chem. 260:8078-8083.

33. Cusack, N. J., and S. M. O. Hourani. 1982. Competitive inhibition by adenosine 5'-triphosphate of the actions on human platelets of 2-chloroadenosine 5 '-diphosphate, 2-azidoadenosine 5'-diphosphate and 2-methylthioadenosine 5'diphosphate. Br. J. Pharmacol. 77:329-333.

34. Macfarlane, D. E., D. C. B. Mills, and P. C. Srivastava. 1982. Binding of 2-azidoadenosine $\left(\beta-{ }^{32} \mathrm{P}\right)$ diphosphate to the receptor on intact human platelets which inhibits adenylate cyclase. Biochemistry. 21:544-549.

35. Zawilska, K. M., G. V. R. Born, and N. A. Begent. 1982. Effect of ADPutilizing enzymes on the arterial bleeding time in rats and rabbits. Br. J. Haematol. 50:317-325.

36. McClure, M. O., A. Kakkar, N. J. Cusack, and G. V. R. Born. 1988. Evidence for the dependence of arterial thrombosis on ADP. Proc. R. Soc. Lond B. Biol. Sci. B234:255-262.

37. Yao, S.-K., J. C. Ober, J. McNatt, C. R. Benedict, M. Rosolowsky, H. V. Anderson, K. Cui, J.-P. Maffrand, W. B. Campbell, L. M. Buja, and J. T. Willerson. 1992. ADP plays an important role in mediating platelet aggregation and cyclic flow variations in vivo in stenosed and endothelium-injured canine coronary arteries. Circ. Res. 70:39-48.

38. Di Minno, G., A. M. Cerbone, P. L. Mattioli, S. Turco, C. Iovine, and M. Mancini. 1985. Functionally thrombasthenic state in normal platelets following the administration of ticlopidine. J. Clin. Invest. 75:328-338.

39. Mills, D. C. B., R. Puri, C. J. Hu, C. Minniti, G. Grana, M. D. Freedman R. F. Colman, and R. W. Colman. 1992. Clopidogrel inhibits the binding of ADP analogues to the receptor mediating inhibition of platelet adenylate cyclase Arterioscler. Thromb. 12:430-436.

40. Defreyn, G., C. Gachet, P. Savi, F. Driot, J. P. Cazenave, and J. P. Maffrand. 1991. Ticlopidine and clopidogrel (SR25990C) selectively neutralize ADP inhibition of $\mathrm{PGE}_{1}$-activated platelet adenylate cyclase in rats and rabbits. Thromb. Haemostasis. 65:186-190.

41. Peerschke, E. I. B. 1985. The platelet fibrinogen receptor. Semin. Hematol. 22:241-259.

42. Hardisty, R., D. Pidard, A. Cox, T. Nokes, C. Legrand, C. Bouillot, A. Pantonella, E. Heilmann, P. Hourdillé, S. Bellucci, and A. Nurden. 1992. A defect of platelet aggregation associated with an abnormal distribution of glycoprotein IIb-IIIa complexes within the platelet: the cause of a lifelong bleeding disorder. Blood. 80:696-708.

43. Janes, S. L., D. J. Wilson, N. Chronos, and A. H. Goodall. 1993. Evaluation of whole blood flow cytometric detection of platelet bound fibrinogen on normal subjects and patients with activated platelets. Thromb. Haemostasis. 70:659-666.

44. Abrams, C., and S. J. Shattil. 1991. Immunological detection of activated platelets in clinical disorders. Thromb. Haemostasis. 65:467-473.

45. Ugarova, T. P., A. Z. Budzynski, S. J. Shattil, Z. M. Ruggeri, M. H. Ginsberg, and E. F. Plow. 1993. Conformational changes in fibrinogen elicited by its interaction with platelet membrane glycoprotein GP IIb-IIIa. J. Biol. Chem. 268:21080-21087

46. Greco, N. J., N. N. Tandon, B. W. Jackson, and G. A. Jamieson. 1992 Low structural specificity for nucleoside triphosphates as antagonists of ADPinduced platelet activation. J. Biol. Chem. 267:2966-2970.

47. Chediak, J., M. C. Telfer, B. Vander Lann, B. Maxey, I. Cohen. 1979. Cycles of agglutination-disagglutination induced by ristocetin in thrombasthenic platelets. Br. J. Haematol. 43:113-126.

48. Cristalli, G., and D. C. B. Mills. 1993. Identification of a receptor for ADP on blood platelets by photoaffinity labelling. Biochem. J. 291:875-881

49. Gachet, C., J. P. Cazenave, P. Ohlmann, G. Hilf, T. Wieland, and K. H. Jakobs. 1992. ADP receptor-induced activation of guanine-nucleotide-binding proteins in human platelet membranes. Eur. J. Biochem. 207:259-263.

50. Brass, L. F., J. A. Hoxie, and D. R. Manning. 1993. Signaling through $\mathrm{G}$ proteins and $\mathrm{G}$ protein-coupled receptors during platelet activation. Thromb. Haemostasis. 70:217-223.

51. McGuire, T. F., S. J. Corey, and S. M. Sebti. 1993. Lovastatin inhibits platelet-derived growth factor (PDGF) stimulation of phosphatidylinositol 3-kinase activity as well as association of $\mathrm{p} 85$ subunit to tyrosine-phosphorylated PDGF receptor. J. Biol. Chem. 268:22227-22230. 